\title{
Parental involvement and bullying among middle- school students in North Africa
}

H. Abdirahman, ${ }^{1}$ L.C. Fleming ${ }^{2}$ and K.H. Jacobsen ${ }^{7}$

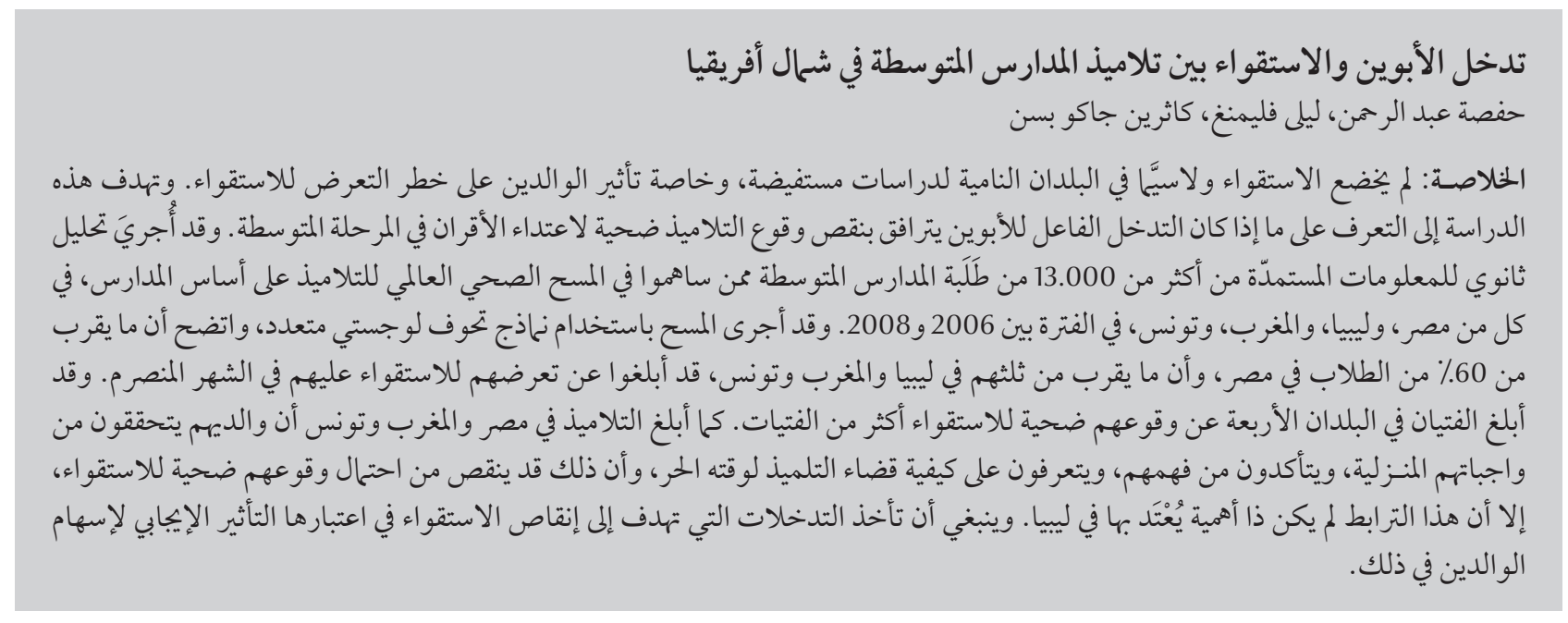

ABSTRACT Bullying, especially in developing countries, has not been much examined, especially the influence of parents on the risk of being bullied. The aim of this study was to determine whether active parenting is associated with reduced peer victimization among middle-school students in North Africa. A secondary analysis of data from more than 13000 middle-school students who participated in the Global School-based Student Health Survey (GSHS) in Egypt, Libya, Morocco and Tunisia between 2006 and 2008, was conducted using multiple logistic regression models. About $60 \%$ of students in Egypt and one-third of students in Libya, Morocco and Tunisia reported having been bullied in the past month. In all 4 countries, boys reported more peer victimization than girls. In Egypt, Morocco and Tunisia, students who reported that their parents checked their homework, were understanding, and knew how the student spent free time had a reduced likelihood of peer victimization but this association was not significant in Libya. Interventions for reducing bullying should consider the positive impact of involved parents.

\section{Intimidation des élèves au collège en Afrique du Nord et implication des parents}

RÉSUMÉ Ni l'intimidation ni l'influence des parents sur le risque d'être victime d'intimidation n'ont été beaucoup étudiées, en particulier dans les pays en développement. La présente étude visait à déterminer si l'implication des parents était associée à une réduction de la victimisation par les pairs chez des élèves de collège (11-16 ans) d'Afrique du Nord. Une analyse secondaire des données fournies par plus de 13000 de ces élèves, qui ont participé à l'enquête mondiale sur la santé à l'école en Égypte, en Libye, au Maroc et en Tunisie entre 2006 et 2008, a été menée à l'aide de modèles de régression logistique multiple. Près de $60 \%$ des élèves en Égypte et un tiers des élèves en Libye, au Maroc et en Tunisie ont rapporté avoir été intimidés au cours du mois écoulé. Dans l'ensemble des quatre pays, les garçons étaient plus souvent victimes de leurs pairs que les filles. En Égypte, au Maroc et en Tunisie, les élèves affirmant que leurs parents vérifiaient leurs devoirs, étaient compréhensifs et savaient comment ils passaient leur temps libre étaient moins susceptibles d'être victimes de leurs pairs. En revanche, cette association n'était pas significative en Libye. Les interventions visant à réduire l'intimidation devraient prendre en compte l'impact positif de l'implication des parents. 


\section{Introduction}

Bullying of adolescents by their peers has been shown to be a significant problem around the world $[1,2]$. Recent studies from more than 60 countries with a wide range of income levels have found that approximately 1 of every 3 early adolescents has been a victim of bullying $[1,2]$. School bullies are students who purposely target another student, a victim, for recurrent psychological and/ or physical attacks, which may take the form of hitting, kicking, pushing, name calling and teasing, among others [3]. These actions between a bully and a victim occur because of an imbalance of power $[3,4]$. Thus, some students are best described as "bully-victims" who are perpetrators of bullying against weaker students and at the same time are victims of bullying by more powerful students [4]. This paper will focus on the victims of bullying, including bully-victims, with a goal of examining the prevalence of peer victimization and the impact of parental involvement on bullying of middle-school students in the Egypt, Libya, Morocco and Tunisia.

Multi-country studies generally find that boys are more likely than girls to be bullied and that younger adolescents are more likely to be bullied than older students $[1,2]$. Victims of bullying are more likely than other students to report mental health disorders $[5,6]$ and emotional distress [7] and to engage in unhealthy behaviours such as smoking, drinking, and drug use [2,5].

A variety of factors contributing to peer victimization have been identified in the literature, including reporting negative school experiences [8] such as social marginalization at school $[7,9]$, not being accepted by peers [10], being teased for being overweight or obese [11], and exhibiting low self-esteem [5,12-14]. Family socioeconomic standing and relations have also been found to play a role in bullying-victimization. Adolescents from families of lower socioeconomic status are at increased risk of bullying [1,12], as are those from single parent homes [9]. Some types of negative family interactions $[5,9]$, such as bullying behaviour among siblings [6] or family members teasing a child about his or her appearance [12], are also associated with an increased likelihood of bullying by peers.

The influence of parents on the risk of peer victimization is relatively understudied. The few publications on this topic, nearly all of which are from high-income countries, suggest that parents do have an impact on the likelihood of their offspring being bullied. For example, previous reports suggest that male victims of bullying are more likely to have overprotective mothers and distant fathers [15], and that youth who experience physical and emotional maltreatment from parents are also at increased risk of peer victimization [16]. Other studies have demonstrated that high levels of parental emotional support, increased parental encouragement, and better parent-child communication can reduce the risk of a student being bullied and minimize emotional distress and behavioural problems in the bullied student $[5,9,17]$. These findings emphasize the importance of exploring further parental involvement in relation to peer-victimization of their offspring.

The literature on bullying in general is incomplete. In particular, while several large multi-country studies have suggested that there are considerable similarities in the bullying experience of early adolescents around the world, bullying in some world regions - especially in developing countries - remains nearly unexamined. The aim of this paper is to determine whether parental involvement is associated with peer victimization among middle-school students in the 4 North African countries that participated in the Global School Student Health Survey (GSHS) [http://www. who.int/chp/gshs/en/] before 2009: Egypt, Libya, Morocco and Tunisia. This study will fill several gaps in the literature on bullying by examining bullying in an understudied world region (North Africa) and by exploring new questions about parental involvement and bullying that have not been previously examined in any country.

\section{Methods}

\section{Survey instrument}

In each country that participates in the GSHS, the study is coordinated and conducted by the country's Ministry of Health and/or Ministry of Education with technical support provided by the World Health Organization (WHO) and the United States Centers for Disease Control and Prevention (CDC). To allow for cross-country comparisons, a standardized question database is used by all participating countries. There are 10 core modules in the GSHS questionnaire: alcohol use, dietary behaviours, drug use, hygiene, mental health, physical activity, protective factors, sexual behaviours, tobacco use, and violence and unintentional injury. Individual countries can choose which core modules to include in their survey, and also have the option of adding questions from an expanded question database. Once an individual country's questionnaire content is selected, the questions are translated into the local language and pilot tested to ensure student understanding [18].

\section{Sampling strategy}

In each country, a 2-stage cluster sample design is used to select a nationally representative sample of middle-school students in the country. First, schools are randomly selected from a list of all schools in the country using a method that ensures a mix of small and large schools and the inclusion of schools from all geographical regions, proportional to population size. Then individual classes from within those schools are randomly selected for participation from a list of the classes with the highest 
proportion of students between 13 and 15 years of age. All students in the randomly-selected classes are eligible for participation no matter what their individuals ages are, so the final study population contains students aged 11 to 17 years. As an example, 50 schools from across Libya were randomly sampled from a list of all schools in the country containing grades 7 , 8, or 9 [19]. All 50 sampled schools agreed to participate, and at least 1 class from each school was selected for participation. In total, 98\% of the students who were enrolled in the sampled classes completed the GSHS questionnaire [19].

\section{Ethical considerations}

The study protocol was approved by each government's Ministry of Health and/or Ministry of Education. Students were assured that participation was voluntary and not required, and that they could skip questions in the survey if they did not wish to answer them. Students were also assured that their answers would remain anonymous and confidential, and that data would not be able to be linked to individuals [18]. Students were recruited in their classrooms, and those who consented to participate were given 1 class session during the usual school day in which to complete their own questionnaire forms.

\section{Study questions}

Two groups of questions were the focus of our analysis: peer victimization (from the violence and unintentional injury module) and parental involvement (from the protective factors module). Students were classified as victims of bullying if they responded to the question "How many days have you been bullied in the last 30 days?" with any answer greater than or equal to 1 day. Three questions were used to assess parental involvement: 1) "During the past 30 days how often did your parents or guardians check to see if your homework was done?", 2) "During the past 30 days, how often did your parents or guardians understand your problems and worries?" and 3) "During the past 30 days, how often did your parents or guardians know what you were doing with your free time?" These questions had possible responses of never, rarely, sometimes, most of the time and always. Each variable was recoded into dichotomous variables with never, rarely and sometimes indicating low levels of parental involvement and answers of most of the time and always indicating high levels of parental involvement.

\section{Data analysis}

Secondary analysis of the GSHS datasets was conducted using SPSS, version 18. Chi-squared tests were used to compare the prevalence of bullying and parental involvement across categories of age and sex. Multiple logistic regression models were used to examine whether parental involvement was a predictor for a student being a victim of bullying after adjusting for age and sex. All analyses were conducted separately for each country.

\section{Results}

\section{Demographic data}

The demographic data of the study populations are presented in Table 1. The proportion of male and female participants in Egypt, Morocco and Tunisia were fairly equal but Libya had substantially more female participants. The vast majority of the students were in the 13-15 year age group, but Egypt's sample was skewed to younger age and Morocco's skewed to older age. Thus, multivariate regression models were used to adjust for sex and age in further analysis.

\section{Bullying}

About one-third of the students in Libya, Morocco and Tunisia reported having been bullied in the past month (Table 2). The rate of bullying in Egypt was about twice as high (60.3\%). In all 4 countries, a higher proportion of boys

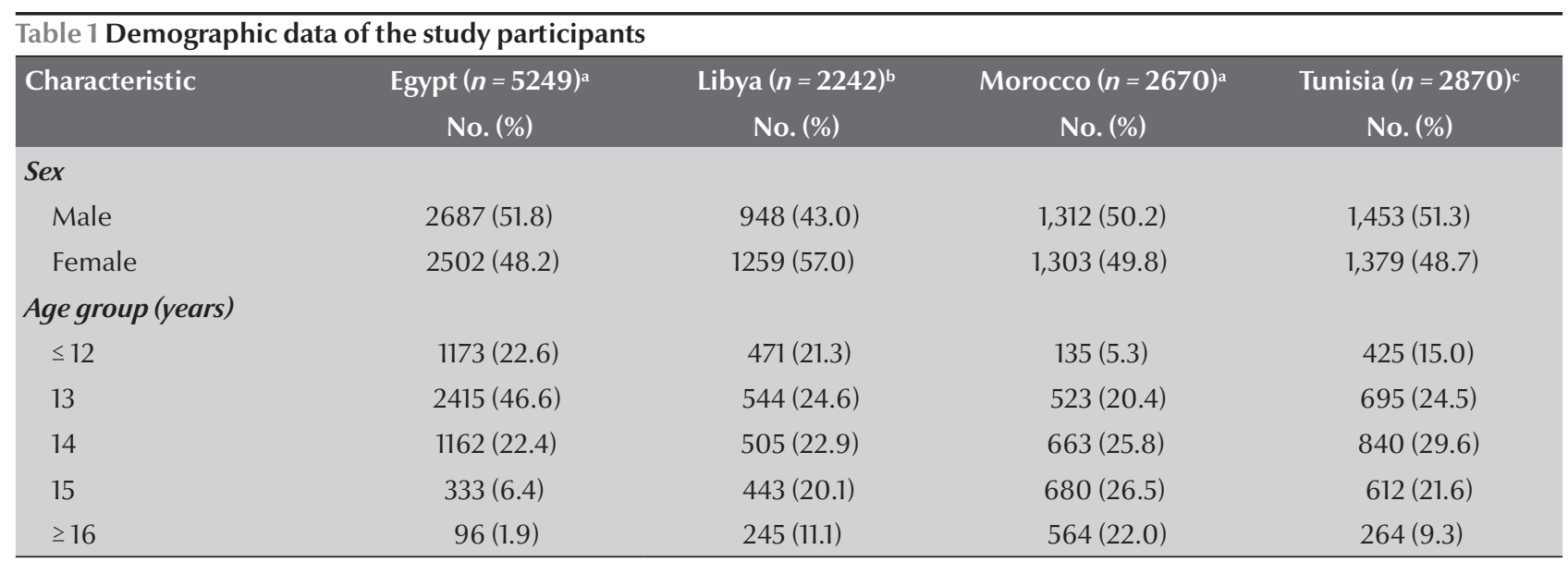

${ }^{a}$ Survey year $=2006$.

${ }^{b}$ Survey year $=2007$.

'Survey year $=2008$. 
than girls reported being bullied. The reported rate of victimization increased with age in Egypt, but did not vary with age in the other 3 countries.

\section{Parental involvement}

The rates of reported parental involvement in the lives of their children were lowest in Morocco, highest in Tunisia and intermediate in Libya and Egypt (Table 3). In general, students did not report a difference in parental homework checks by sex, but girls were somewhat more likely than boys to report that their parents were understanding and that their parents monitored their free time. These results varied somewhat by country. Overall, older students reported less homework checking, less parental understanding and less parental monitoring of their free time than younger students.

\section{Bullying and parental involvement}

The adjusted and unadjusted results of logistic regression models of parental involvement and peer victimization are presented in Table 4. Parental involvement was associated with a decreased likelihood of bullying in Egypt, Morocco and Tunisia, but was not statistically significant in Libya.

\section{Discussion}

Inthis analysis ofGSHS datafrom 4 countries in North Africa, about one-third of middle-school students reported having been bullied in the previous month. This prevalence is similar to previous studies from countries in other high-income and low-income regions of the world $[1,2]$. However, the rate of bullying reported in Egypt (60.3\%) was considerably higher than those of the other North African countries examined in this study, as well as being higher than the rates reported from nearly all other studies of bullying prevalence from around the world $[1,2]$. Because few previous studies have examined bullying in North Africa, it is difficult to explain Egypt's high rate of reported peer victimization. However, concerns about school-based violence in Egypt have been raised by Egypt's National Center for Social and Criminal Research, which in a recent study of students in primary and secondary school found that $69 \%$ of students reported being bullied or experiencing aggression from other students [20]. That report hypothesized that socioeconomic inequalities, the home environment and other external forces were responsible for most acts of school violence, and noted that schools with students from a diversity of socioeconomic backgrounds experienced higher rates of school aggression. The report called for new protocols for addressing bullying and other forms of peer victimization among children and adolescents in schools, especially since $42 \%$ of bullying episodes in that study were reported to have occurred when a teacher was nearby [20].

The GSHS analysis found that boys in North Africa were more likely than girls to be victimized. Most studies of differences in bullying by sex from around the world also found a higher rate of victimization among boys than in girls $[1,2]$. This may be due to boys experiencing more direct bullying such as verbal and physical attacks while girls experience indirect bullying such as social exclusion or the spread of rumours; in addition "indirect" bullying may be less likely to be reported [21]. Peer victimization increased with age in Egypt and did not change with age in the other 3 study countries. These findings do not match previous studies from other parts of the world, which almost uniformly find that bullying rates in early adolescents decrease with age [2]. However, the GSHS findings from

\begin{tabular}{|c|c|c|c|c|}
\hline \multirow[t]{3}{*}{ Variable } & \multicolumn{4}{|c|}{ Experienced bullying in past month } \\
\hline & Egypt $(n=5249)$ & Libya $(n=2242)$ & Morocco $(n=2670)$ & Tunisia $(n=2870)$ \\
\hline & $\%$ & $\%$ & $\%$ & $\%$ \\
\hline Total bullied & 60.3 & 34.5 & 31.9 & 30.6 \\
\hline \multicolumn{5}{|l|}{ Sex } \\
\hline Female & 57.3 & 30.8 & 23.4 & 25.4 \\
\hline Male & 62.9 & 39.4 & 41.1 & 36.8 \\
\hline$P$-value for sex (2-sided $\chi^{2}$ test) & $0.001^{*}$ & $<0.001^{*}$ & $<0.001^{*}$ & $<0.001^{*}$ \\
\hline \multicolumn{5}{|l|}{ Age group (years) } \\
\hline$\leq 12$ & 62.3 & 33.8 & 23.3 & 32.7 \\
\hline 13 & 56.8 & 34.6 & 29.6 & 30.0 \\
\hline 14 & 59.1 & 31.8 & 32.1 & 29.5 \\
\hline 15 & 76.8 & 37.7 & 34.0 & 31.0 \\
\hline$\geq 16$ & 81.4 & 35.0 & 33.1 & 32.3 \\
\hline$P$-value for age (2-sided $\chi^{2}$ test) & $<0.001^{*}$ & 0.440 & 0.149 & 0.805 \\
\hline
\end{tabular}

*Statistically significant at the $a=0.05$ level 


\begin{tabular}{|c|c|c|c|c|}
\hline Parental involvement/sex \& age group & $\begin{array}{c}\text { Egypt } \\
(n=5249)\end{array}$ & $\begin{array}{c}\text { Libya } \\
(n=2242)\end{array}$ & $\begin{array}{l}\text { Morocco } \\
(n=2670)\end{array}$ & $\begin{array}{c}\text { Tunisia } \\
(n=2870)\end{array}$ \\
\hline & $\%$ & $\%$ & $\%$ & $\%$ \\
\hline $\begin{array}{l}\text { Parents check school assignments most of the time } \\
\text { or always }\end{array}$ & 45.8 & 35.4 & 30.3 & 57.1 \\
\hline Females & 45.5 & 35.7 & 30.1 & 55.2 \\
\hline Males & 46.1 & 35.1 & 30.4 & 58.9 \\
\hline$P$-value for sex $\left(2\right.$-sided $\chi^{2}$ test $)$ & 0.685 & 0.794 & 0.894 & 0.048 \\
\hline Age $\leq 12$ years & 50.5 & 34.4 & 35.9 & 70.6 \\
\hline Age 13 years & 48.7 & 35.7 & 36.8 & 65.0 \\
\hline Age 14 years & 40.7 & 38.1 & 31.5 & 55.5 \\
\hline Age 15 years & 34.8 & 34.0 & 24.6 & 46.1 \\
\hline Age $\geq 16$ years & 25.3 & 35.2 & 29.3 & 43.2 \\
\hline$P$-value for age ( 2 -sided $\chi^{2}$ test) & $<0.001^{*}$ & 0.720 & $<0.001^{*}$ & $<0.001^{*}$ \\
\hline $\begin{array}{l}\text { Parents understand their problems and worries most } \\
\text { of the time or always }\end{array}$ & 31.6 & 33.4 & 27.3 & 38.4 \\
\hline Females & 33.5 & 35.7 & 27.4 & 39.0 \\
\hline Males & 30.0 & 30.0 & 27.2 & 37.9 \\
\hline$P$-value for sex $\left(2\right.$-sided $\chi^{2}$ test $)$ & $0.009^{*}$ & $0.006^{*}$ & 0.922 & 0.547 \\
\hline Age $\leq 12$ years & 30.1 & 38.1 & 31.8 & 46.6 \\
\hline Age 13 years & 35.0 & 34.4 & 31.4 & 42.6 \\
\hline Age 14 years & 29.0 & 30.4 & 28.2 & 39.1 \\
\hline Age 15 years & 26.1 & 32.2 & 26.5 & 30.4 \\
\hline Age $\geq 16$ years & 23.0 & 29.9 & 22.9 & 31.3 \\
\hline$P$-value for age ( 2 -sided $\chi^{2}$ test $)$ & $<0.001^{*}$ & 0.092 & $0.023^{*}$ & $<0.001^{*}$ \\
\hline $\begin{array}{l}\text { Parents know how they spend their free time most of } \\
\text { the time or always }\end{array}$ & 47.8 & 44.2 & 40.8 & 50.3 \\
\hline Females & 53.8 & 45.8 & 44.4 & 53.1 \\
\hline Males & 42.6 & 42.3 & 37.2 & 47.2 \\
\hline$P$-value for sex $\left(2\right.$-sided $\chi^{2}$ test $)$ & $<0.001^{*}$ & 0.117 & $<0.001^{*}$ & $0.002^{*}$ \\
\hline Age $\leq 12$ years & 52.4 & 44.2 & 60.9 & 61.3 \\
\hline Age 13 years & 51.0 & 49.6 & 45.9 & 52.1 \\
\hline Age 14 years & 44.3 & 43.3 & 40.7 & 52.6 \\
\hline Age 15 years & 32.4 & 41.6 & 37.7 & 43.9 \\
\hline Age $\geq 16$ years & 23.6 & 38.6 & 36.5 & 36.6 \\
\hline$P$-value for age (2-sided $\chi^{2}$ test) & $<0.001^{*}$ & $0.031^{*}$ & $<0.001^{*}$ & $<0.001^{*}$ \\
\hline
\end{tabular}

*Statistically significant at the $a=0.05$ level.

Egypt are consistent with those of the Egyptian government report, which found that acts of bullying and school aggression increased with age [20].

Parental involvement in the GSHS analysis was, as expected, reported to be lower among older children. Reported parental involvement did not differ by the sex of the child. This is somewhat unexpected since previous studies of parenting practices in the Middle East and North Africa typically show differences in parenting practices for female and male children [22], as do studies of children's perceptions of parenting practices from Western countries [3].

Parenting styles in North Africa and the Middle East - and in nearly every population worldwide - range from flexible to controlling [22]. The typical parenting profile may differ by socioeconomic status and other household characteristics. For example, parents in the region who have higher levels of education and higher socioeconomic status may be more likely than other parents to encourage their children's self-efficacy [23]. A study of adolescents from 8 countries in the Middle East and North Africa also found an association between parenting styles and the sociopolitical system of a country [22]. In general, parents from socially 
conservative, undemocratic nations demonstrated more controlling parenting patterns than parents from democratic and liberal political systems, who exhibited more flexible parenting [22]. Urbanization may also influence parenting practices. A study from Egypt found that boys in rural areas and girls in urban areas were more likely than other children to experience authoritarian parenting styles [24].

The GSHS data show that in Egypt, and also in Morocco and Tunisia, parental involvement is associated with a reduced likelihood of peer victimization which are consistent with findings from previous studies from Western countries indicating that children who experience greater parental encouragement [5], emotional support $[5,17]$, and parent-child communication [9] are less likely to be bullied. Both the degree to which parents are involved in their children's lives and the type of parental involvement are important. Excessive parental involvement and over-protectiveness that restricts a child's self-efficacy both seem to increase the risk of a child being victimized [3]. Adolescents who have more involvement in their own decision-making are less likely to be victimized by peers [25]. There was no statistically significant association between parental involvement and peer victimization in Libya. The varying levels of urbanization, sociopolitical status and economic development among the GSHS study countries in North Africa may explain some of the differences between Libya and the other study countries. Libya has a much more urban population (78\%) than Egypt (43\%), Morocco (56\%), and Tunisia (67\%), and it also had a higher gross national income per capita in the survey year (US\$ 8200) than Egypt (US\$1290), Morocco (US\$ 2120) and Tunisia (US\$ 3540) [26]. The previous studies from the North Africa and Middle East region that suggest that wealthier, more urbanized populations have parenting styles that allow for more child independence [22-24] may help to explain why the Libya GSHS data did not show a significant association between parental involvement and peer victimization.

The GSHS study has 2 significant strengths. One is that the use of validated and standardized questions allows for comparison of results across countries, including the comparison of results among the 4 North African countries examined in this paper. Another is the use of sampling techniques that result in nationally-representative data and large numbers of participants.

However, there are also 2 major factors that may limit the validity and applicability of the results of this study, one related to the survey instrument and one related to the study design. In terms of the questionnaire, 3 key issues may have affected the analysis. First, the GSHS questionnaire only asked about the children's perceptions of parental involvement in their lives. These perceptions were not verified against the parents' perceptions of their involvement. However, this may not be a major drawback since the approach was appropriate for the goal of the questions, which was to assess students' perceptions of both bullying and parental involvement. Second, the questionnaire did not ask about whether the student was a perpetrator of bullying, only whether the student was a victim, so it was not possible to conduct separate analyses for bullies, victims and bully-victims. Previous studies have suggested that victims and bully-victims may have different social and behavioural characteristics and it was not possible to explore those in this study. Some of the observed linkages between parental involvement and peer victimization may have been different for victims and bully-victims had it been possible to examine those students separately. Third, only 3 questions in the survey addressed parental involvement and these questions are not sufficient to fully capture how parents engage with their early adolescent children. In terms of study design, the GSHS uses a cross-sectional approach, surveying children at one point in time rather than following them longitudinally. Although statistically 
significant associations were identified in the dataset, the cross-sectional design means that it is not possible to examine the time dimension of whether bullied students' parents become more involved in their lives or whether having involved parents protects children from being victimized by peers.

Despite these limitations, this is the first study to compare bullying rates and parental involvement in North Africa and it may have important implications for schools and institutions that serve adolescents in the study countries. First, the GSHS data from Egypt, Libya,
Morocco and Tunisia highlight the student populations that are more likely to be victimized, and that knowledge could facilitate the development of appropriate interventions for at-risk youth. Second, the finding that parental involvement is associated with a decreased risk of victimization in the study countries suggests that including parents as partners in anti-bullying campaigns may be important to their success. Third, the high prevalence of victimization in Egypt and the lack of association between parental involvement and bullying in Libya both highlight the need for more research on bullying in this region of the world. Future studies in the region should compare student and parent perspectives on parental involvement and bullying, and should ask questions that allow researchers to more carefully categorize parenting styles and bullying profiles. In the meantime, the high rate of bullying in Egypt supports the need for immediate intervention in this population.

\section{Acknowledgement}

Competing interests: None to declare.

\section{References}

1. Due $\mathrm{P}$ et al. Socioeconomic inequality in exposure to bullying during adolescence: a comparative, cross-sectional, multilevel study in 35 countries. American Journal of Public Health, 2009, 99(5):907-913.

2. Fleming LC, Jacobsen KH. Bullying among middle-school students in low and middle income countries. Health Promotion International, 2010, 25(1):73-84.

3. Smith PK, Myron-Wilson R. Parenting and school bullying. Clinical Child Psychology and Psychiatry, 1998, 3(3):405-417.

4. Olweus D. Bullying at school: what we know and what we can do. Cambridge, MA, Blackwell Publishing, 1993.

5. Cassidy T. Bullying and victimisation in school children: the role of social identity, problem-solving style, and family and school context. Social Psychology of Education, 2009, 12(1):63-76.

6. Duncan RD. Peer sibling aggression: an investigation of intraand extra-familial bullying. Journal of Interpersonal Violence, 1999, 14(8):871-886.

7. Juvonen J, Graham S, Schuster MA. Bullying among young adolescents: the strong, the weak, and the troubled. Pediatrics, 2003, 112(6 pt 1):1231-1237.

8. Harel-Fisch $\mathrm{Y}$ et al. Negative school perceptions and involvement in school bullying: A universal relationship across 40 countries. Journal of Adolescence, 2011, 34(4):639-652.

9. Spriggs AL et al. Adolescent bullying involvement and perceived family, peer and school relations: commonalities and differences across race/ethnicity. Journal of Adolescent Health, 2007, 41(3):283-293.

10. Olthof T, Goossens FA. Bullying and the need to belong: early adolescents' bullying-related behavior and the acceptance they desire and receive from particular classmates. Social Development, 2008, 17(1):24-46.

11. Janssen I et al. Associations between overweight and obesity with bullying behaviors in school aged children. Pediatrics, 2004, 113:1187-1194.

12. Jankauskiene $\mathrm{R}$ et al. Associations between school bullying and psychosocial factors. Social Behavior and Personality, 2008, 36(2):145-162.

13. Seals D, Young J. Bullying and victimization: prevalence and relationship to gender, grade level, ethnicity, self-esteem, and depression. Adolescence. 2003, 38(152):735-747.

14. Uba I et al. Effect of self-esteem on the relationship between depression and bullying among teenagers in Malaysia. Asian Social Science, 2010, 6(12):77-85.
15. Duncan RD. The impact of family relations on school bullies. In: Espelage DL, Swearer SM. Bullying in American schools: A social-ecological perspective on prevention and intervention. Mahwah, NJ, Lawrence Erlbaum Associates, 2004.

16. Shields A, Cicchetti D. Parental maltreatment and emotion dysregulation as risk factors for bullying and victimization in middle childhood. Journal of Clinical Child Psychology, 2001, 30(3):349-363.

17. Yeung R, Leadbeater B. Adults make a difference: the protective effects of parent and teacher emotional support on emotional and behavioral problems of peer-victimized adolescents. Journal of Community Psychology, 2010, 38(1):80-98.

18. Global School-based Student Health Survey (GSHS): purpose and methodology. Geneva, World Health Organization (http:// www.who.int/chp/gshs/methodology/, accessed 5 July 2011).

19. Daganaee MIS. The final report of Global School-Based Health Survey (GSHS) 2007. Tripoli, Libya, Secretariat of Health and Environment, 2007 (http://www.who.int/chp/gshs/GSHS_ Libya_report_2007.pdf, accessed 16 December 2012).

20. Zayed A et al. [Violence among students in schools]. Cairo, National Center for Social and Criminal Research, 2004 [In Arabic].

21. Van der Wal MF, de Wit CAM, Hirasing RA. Psychosocial health among young victims and offenders of direct and indirect bullying. Pediatrics, 2003, 111(6):1312-1317.

22. Dwairy M et al. Parenting styles in Arab societies: a first crossregional research study. Journal of Cross Cultural Psychology, 2006, 37:230-247.

23. Assadi SM et al. Effect of sociocultural context and parenting style on scholastic achievement among Iranian adolescents. Social Development, 2007, 16(1):169-180.

24. Dwairy M, Menshar KE. Parenting style, individuation, and mental health of Egyptian adolescents. Journal of Adolescence, 2006, 29:103-117.

25. Nation $\mathrm{M}$ et al. Bullying in school and adolescent sense of empowerment: an analysis of relationships with parents, friends, and teachers. Journal of Community and Applied Social Psychology, 2008, 18:211-232.

26. World Development Indicators. Washington DC, The World Bank, 2011. 